\title{
Comparison of Reference Current Extraction Methods for Shunt Active Power Filters
}

\author{
B. Geethalakshmi and M. Kavitha
}

\begin{abstract}
Generation of current references constitutes an important part in the control of active power filters (APFs) used in power system, since any inaccuracy in reference currents yields to incorrect compensation. In this paper, two different harmonic detection methods for generating reference currents have been evaluated. The approach is based on the measurement of line currents and performs the compensation of the selected harmonics using closed-loop control. MATLAB/SIMULINK power system toolbox is used to simulate the proposed system. Simulation results show that the dominant harmonics in the line current are reduced significantly and thereby there is a marked reduction in the total harmonic distortion.
\end{abstract}

Index Terms-Active power filters, harmonic compensation, multilevel inverters, non linear loads and power quality.

\section{INTRODUCTION}

POWER QUALITY (PQ) is an important measure of an electrical power system. The term PQ means to maintain purely sinusoidal current waveform in phase with a purely sinusoidal voltage waveform. The deteriorating quality of electric power is mainly because of current and voltage harmonics due to wide spread application of static power converters, zero and negative sequence components originated by the use of single phase and unbalanced loads, reactive power, voltage sag, voltage swell, flicker, voltage interruption etc. [1].

To improve the power quality traditional compensation methods such as passive filters, synchronous capacitors, phase advancers, etc were employed [2]. However traditional controllers include many disadvantages such as fixed compensation, bulkiness, electromagnetic interference and possible resonance etc., Active power filters (APF) have proved to be an attractive alternative to compensate for current and voltage disturbances in power distribution systems [2]. Two fundamental configurations of stand-alone APFs, either active or passive, have evolved: the series and the shunt filter. The shunt active filter shown in

Fig.1 is recognized as a cost effective solution for harmonic compensation in low and medium power systems [3]. It has simple structure and construction, similar to a

Manuscript received July 30, 2009; revised May 28, 2010.

B. Geethalakshmi is with the Department of Electrical and Electronics Engineering, Pondicherry Engineering College, Pondicherry, India. (Corresponding author phone: 09443660802 fax: 04132655101 ; e-mail: bgeethalakshmi_pec@yahoo.co.in).

M. Kavitha is with the Department of Electrical and Electronics Engineering, Pondicherry Engineering College, Pondicherry, India. (e-mail: kavithamrgn@gmail.com).
PWM voltage source inverter, with a large dc link capacitor, and connected to the line by means of an inductor.

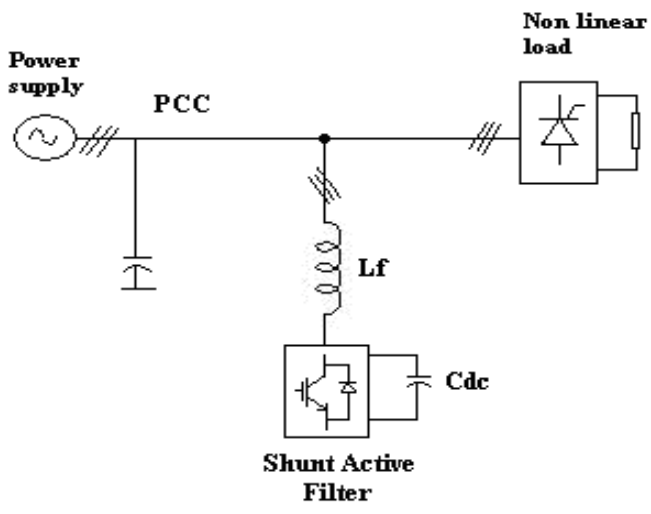

Fig. 1 Block diagram of shunt active power filter

At low voltage levels, conventional two level inverters are used. At medium voltage levels, the conventional two level inverters either require interface transformers between the inverter terminals and the supply terminals or need active devices to be connected in series to achieve the required voltage levels. The multilevel inverters [4] are able to achieve the required voltage levels using devices of low voltage rating. Hence in this proposed work, the APF is realized using the cascaded H-bridge 5-level inverter. Besides, for extracting the harmonics component of the non-sinusoidal load current fast Fourier transform (FFT) and synchronous reference frame (SRF) methods have been used. A closed loop control scheme for selectively eliminating the most harmful harmonics in the line current has been developed. The scope includes evaluating the performance of shunt active power filters with a variety of non-linear loads and under unbalanced supply voltage through MATLAB based simulation.

\section{APF STRATEGY}

\section{A. Active Power Filter}

The increased severity of harmonic pollution in power networks has attracted the attention of power electronics and power system engineers to develop dynamic and adjustable solutions to the power quality problems. Such equipments, generally known as active filters [5-6], are also called active power line conditioners (APLC's), instantaneous reactive power compensators (IRPC's), active power filters (APF's), and active power quality conditioners (APQC's). To effectively compensate the load harmonic currents, the active filter controller should be designed to meet the following three goals:

1. extract and inject load harmonic currents; 
2. maintain a constant dc capacitor voltage;

3. avoid generating or absorbing reactive power with fundamental frequency components.

The shunt active power filter shown in Fig.1has the structure of a three-phase PWM power converter connected to the line by an inductance $\mathrm{L}_{\mathrm{f}}$ rated at about $5 \%$ of the filter power. The dc link storage component is a capacitor, usually of larger value than in a standard power inverter [7]. In this paper, the multilevel inverter acts as active power filter which is connected in parallel with the ac distribution system.

\section{B. Cascaded Multilevel Inverter}

The cascaded multilevel inverter (CMLI) considered in Fig. 1 is one of the most important topology in the family of multilevel inverters. It requires least number of components when compared to diode-clamped and flying capacitors type multilevel inverters [8]. For active power filter application, the bandwidth of the multilevel inverter has to be decided by the highest harmonic to be compensated. Generally, 5th, 7th, 11 th and 13th are the dominant harmonics at the medium voltage power line. For this medium voltage level a five level cascaded H-bridge multilevel inverter with a switching frequency of $600 \mathrm{~Hz}$ is operated as the active filter.

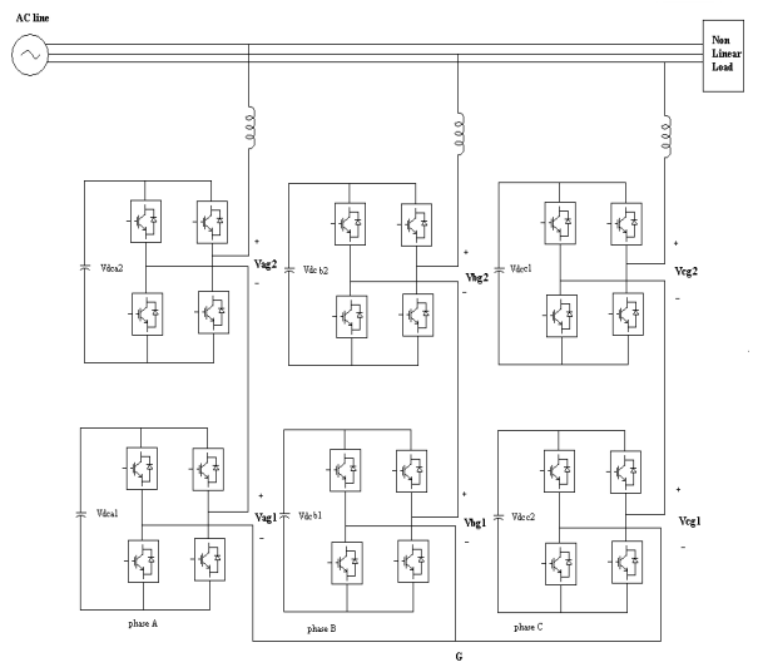

Fig. 2.Schematic of five level shunt active power filter

The multilevel inverter configuration as depicted in Fig.2 is composed of six H-bridges and six dc capacitors. It is connected to the power line through an inductor. By connecting the sufficient number of $\mathrm{H}$-bridges in cascade and using proper modulation scheme, a nearly sinusoidal output voltage waveform can be synthesized. The number of levels in the output phase voltage is $2 s+1$, where $s$ is the number of $\mathrm{H}$-bridges used per phase [9-10]. To obtain 5-level output, two H-bridges are used per phase as shown in Fig.3.

If the dc voltage of each cell is set to the same value $\left(\mathrm{V}_{\mathrm{dca}}\right.$ $=\mathrm{V}_{\mathrm{dca} 2}=\mathrm{E}$ ), then the resulting inverter can operate with five output voltage levels. Table I shows the zero and positive voltage levels obtainable from this inverter as well as the voltage levels from the individual $\mathrm{H}$-bridge cells. As can be seen, positive levels of $\mathrm{E}, 2 \mathrm{E}$ and 0 are the possible output voltages. Due to the inverter symmetry, it is also possible to have negative output voltages of $-\mathrm{E}$ and $-2 \mathrm{E}$ for a total of five voltage levels [8]. The negative voltage levels are excluded in Table I for compactness. The synthesized five level output voltage with its fundamental waveform is shown in Fig.3.

TABLE I INVERTER OUTPUT VOLTAGE

\begin{tabular}{|c|c|c|}
\hline \multirow{2}{*}{$\mathbf{V}_{\mathbf{a g}}$} & $\mathbf{V}_{\mathbf{a g} \mathbf{1}}$ & $\mathbf{V}_{\mathbf{a g} \mathbf{2}}$ \\
\hline \multirow{3}{*}{0} & $\mathrm{E}$ & $-\mathrm{E}$ \\
\cline { 2 - 3 } & 0 & 0 \\
\cline { 2 - 3 } & $-\mathrm{E}$ & $\mathrm{E}$ \\
\hline \multirow{2}{*}{$\mathrm{E}$} & $\mathrm{E}$ & 0 \\
\hline \multirow{2}{*}{$2 \mathrm{E}$} & 0 & $\mathrm{E}$ \\
\cline { 2 - 3 } & $\mathrm{E}$ & $\mathrm{E}$ \\
\hline
\end{tabular}

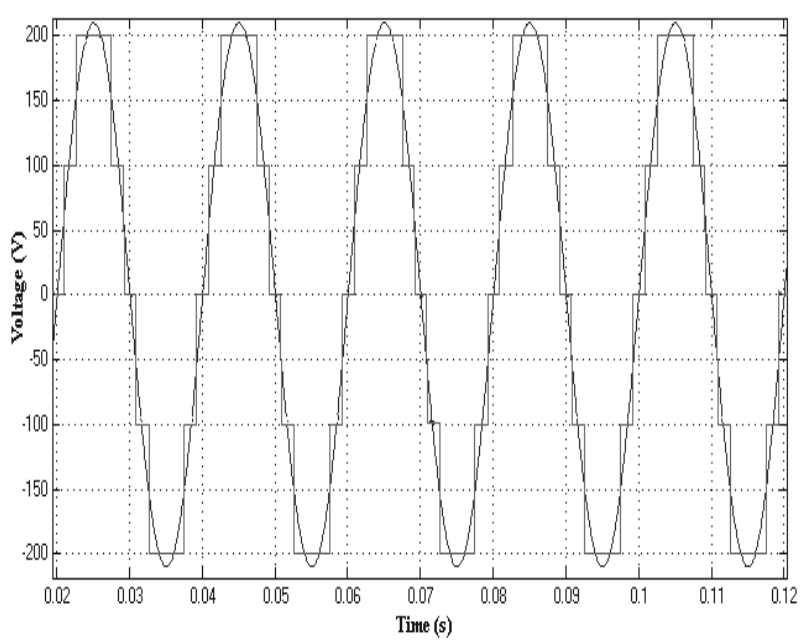

Fig. 3.Five level output voltage with fundamental voltage waveform

\section{METHODS OF REFERENCE CURRENT GENERATION}

The control reference signal for an APF can be obtained either by using frequency domain or time domain techniques. In the proposed work, the reference current is extracted by using both the techniques and the performances obtained through these methods are compared. Under frequency domain analysis fast fourier transform has been considered and synchronous reference frame method is used for time domain analysis [12].

\section{A. Closed Loop Control Scheme Employing FFT}

The basic operational principle of an active power filter requires extracting harmonics to be compensated (or minimized) from the entire current waveform. FFT is a powerful tool for harmonic analysis in active power filters. The closed loop scheme of shunt active power filter using FFT reference current generation is shown in Fig.4. The amplitude and phase information of the harmonic series in a periodic signal can be calculated by using the fourier analyzer block shown in Fig.5 [13,14]. Dominant harmonics have been detected by running the $\mathrm{m}$-file scripts in embedded matlab function block. The detected line current dominant harmonic has been phase shifted to $180^{\circ}$ to generate the reference currents as shown in Fig.5. Thus the active power filter acts as a harmonic current source, injecting into the line harmonic with the same amplitude and opposite phase. 


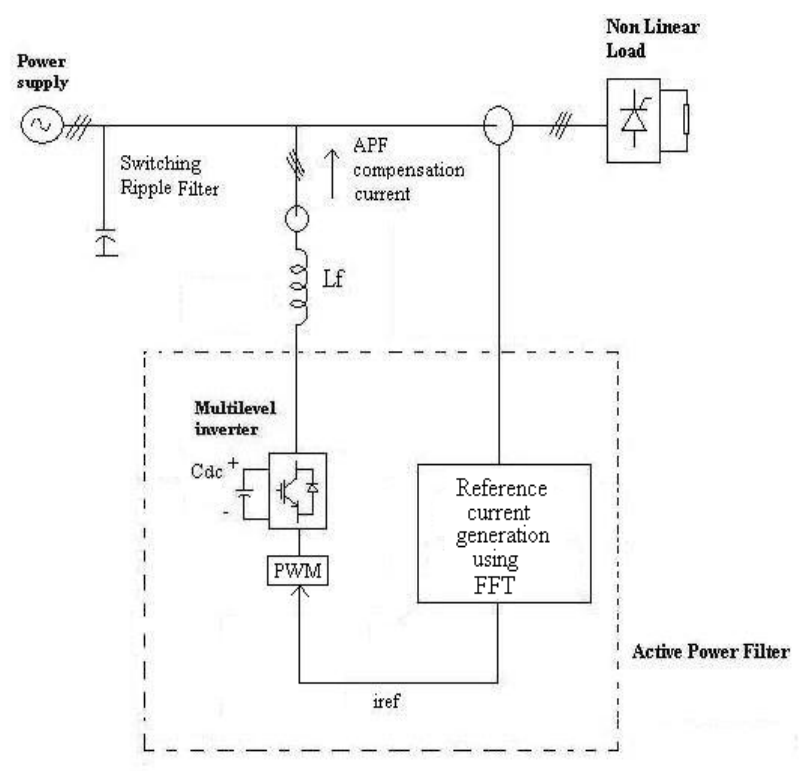

Fig. 4.Shunt active power filter circuit using FFT method

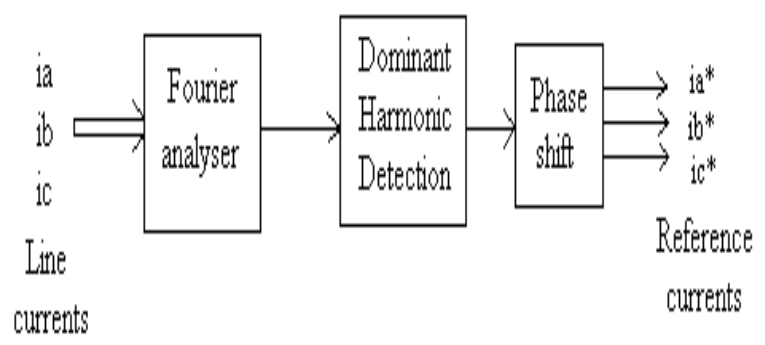

Fig. 5.Reference current generation by FFT method

\section{B. Closed Loop Control Scheme Employing SRF}

The closed loop control scheme for extracting the reference current using synchronous reference fram method is depicted in Fig. 6. The function of the harmonic detection block is separately highlighted in Fig. 7. The SRF method [15] is based on Park's transformation whereby the 3-phase line currents are transformed into 2-phase quantities using Park's transformation.

There are mainly two blocks corresponding to positive and negative sequence components. The positive sequence component of load current is transformed to $\mathrm{d}^{\mathrm{e}}-\mathrm{q}^{\mathrm{e}}$ axes by generating positive sequence phase information $+\theta$ from PLL circuit. The details of mathematical implementation of PLL software in the synchronization of three-phase system is given in [16] and its application in Matlab simulations can be found in package program. AC quantities in positive sequence waveform include all harmonic components while dc quantity is fundamental component of load current. The negative sequence component of the current is also transformed to $\mathrm{d}^{\mathrm{e}}-\mathrm{q}^{\mathrm{e}}$ axes by generating negative sequence phase information $-\theta$ from the PLL. If voltages and currents in the three-phase system are balanced, the output of this block will be zero. Thus the dominant harmonic component is obtained by comparing the positive and negative sequence controller outputs. The component which is in 2-phase form is converted into 3-phase using inverse transformation. This dominant harmonic component of the current is compared with the reference current derived from the dc voltage controller block.
For the active power filter to operate effectively, it is important to maintain the dc capacitor voltage at a constant value. The dc capacitor voltage is directly affected by the real power transferred across the active filter [11]. To keep the voltage constant, ideally, no real power should be transferred. However, due to losses in the switching devices and other components, a small amount of real power is needed.

The actual dc input voltage of multilevel inverter has been compared with the reference voltage as shown in Fig.6. The capacitor voltage regulation is then handled by a simple proportional-integral (PI) controller. The actual filter current is then compared with the reference filter current obtained by comparing the harmonic current (ihd) detected from SRF method and the current obtained from the voltage controller (ihd,ref). This output has been regulated by the current controller (PI) and hence the reference current will be obtained. This reference current has been given as a reference waveform to the pulse width modulator circuit (PWM) of the multilevel inverter. Hence the multilevel inverter generates the desired harmonic compensating current into the line which enables the reduction of dominant harmonic component in the line current.

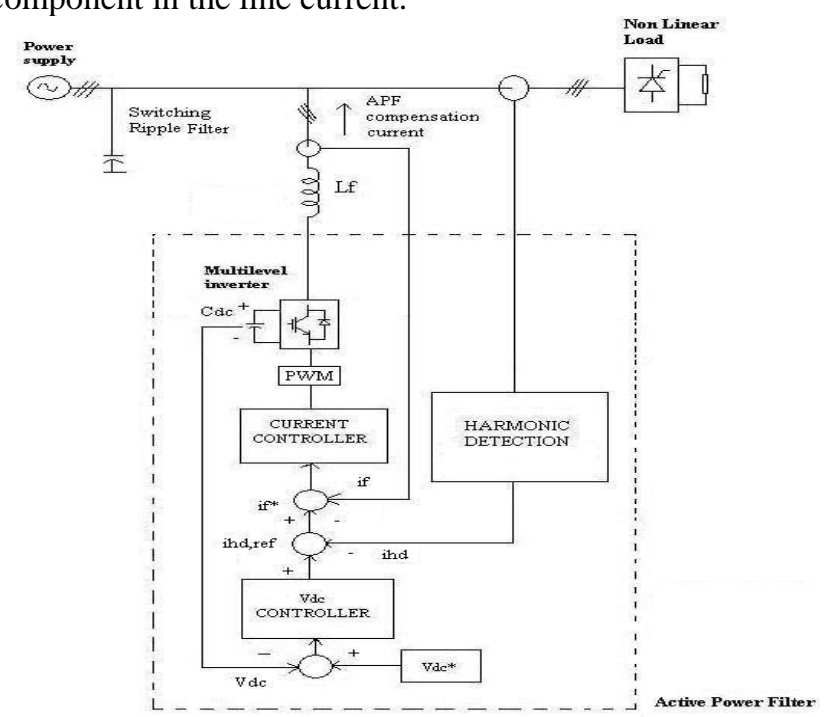

Fig. 6.Closed loop circuit of shunt active power filter using SRF method

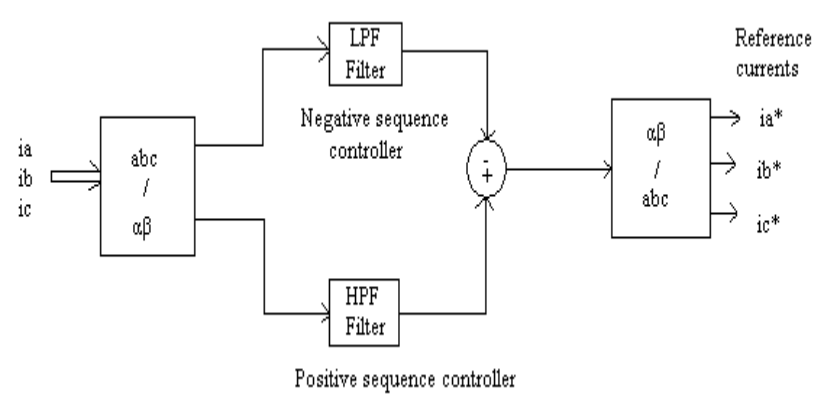

Fig. 7.Harmonic detection by SRF method

\section{Simulation RESUlts}

The presented simulation results have been obtained by using Matlab Simulink power system toolbox software. For the purpose of simulation a three phase $230 \mathrm{~V}, 50 \mathrm{~Hz}$ ac supply has been considered. The proposed APF with closed loop control has been simulated under two different non linear loads namely three phase uncontrolled bridge rectifier and the ac-dc-ac converter which generate non-sinusoidal 
currents with typical THD factors. Also the performance of the proposed APF has been verified under unbalanced supply voltages.

\section{A. Uncontrolled Rectifier Load}

Fig.8 shows the simulated results of the test system considered for an uncontrolled rectifier load by using the proposed two different current generation methods. Without filter the THD of the line current is $15.27 \%$ and the $5^{\text {th }}$ harmonic is found to be the dominant harmonic as displayed in Table II. Input voltage is shown in Fig.8(i) and the non-sinusoidal line current waveform without APF is shown in Fig. 8(ii). From this line current waveform the closed loop controller derives the PWM reference for the multilevel inverter by inverting the $5^{\text {th }}$ harmonic component by $180^{\circ}$. This enables the inverter to generate the desired compensating current for injecting in shunt with the line. Due to the injection of this compensating current a significant improvement is found in the line current waveform as highlighted in Fig. 8(iii). The corresponding filter current waveform is displayed in Fig. 8(iv). With the shunt active power filter the line current THD is significantly reduced to $7.06 \%$ by FFT method and $6.97 \%$ by SRF method. The reductions in the corresponding dominant harmonic components are highlighted in TABLE II.

\begin{tabular}{|c|c|c|c|}
\hline \multirow{3}{*}{$\begin{array}{c}\text { Significant } \\
\text { Harmonics/THD }\end{array}$} & \multicolumn{3}{|c|}{ Magnitude (\%) } \\
\hline & \multirow{2}{*}{$\begin{array}{l}\text { Without } \\
\text { Filter }\end{array}$} & \multicolumn{2}{|c|}{ With Filter } \\
\hline & & FFT & SRF \\
\hline $5^{\text {th }}$ & 11.78 & 3.07 & 3.06 \\
\hline $7^{\text {th }}$ & 4.70 & 1.27 & 1.17 \\
\hline $11^{\text {th }}$ & 1.22 & 0.57 & 0.44 \\
\hline $13^{\text {th }}$ & 0.54 & 0.40 & 0.29 \\
\hline $15^{\text {th }}$ & 1.42 & 0.30 & 0.19 \\
\hline THD & 15.27 & 7.06 & 6.97 \\
\hline
\end{tabular}
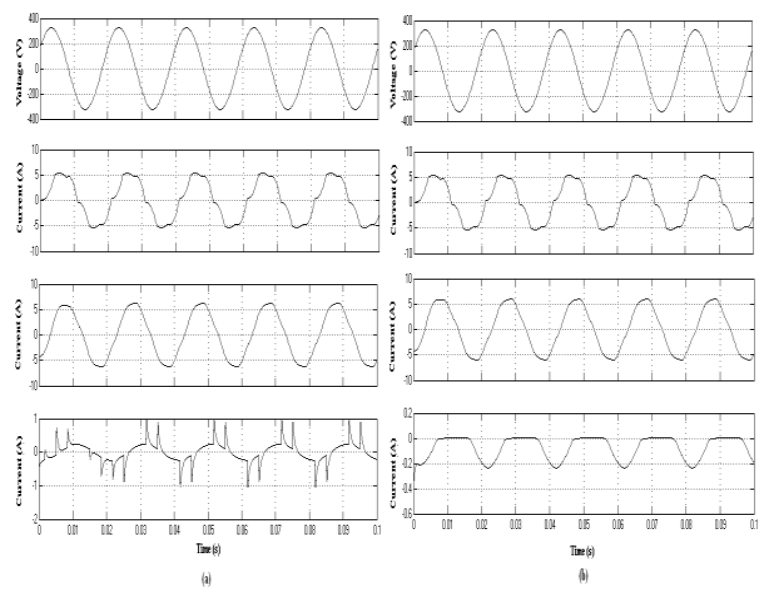

Fig. 8. Uncontrolled Rectifier (a) FFT method (b) SRF method: i) input voltage ii) Line current without filter iii) Line current with filter iv) APF current

\section{B. AC-DC-AC converter}

Ac-dc-ac converter is used as another nonlinear load in the test system and its simulated results are shown in Fig.9. Without the filter, the line current waveform is non sinusoidal due to the presence of harmonics and is depicted in Fig. 9(ii). As given in the Table III, $5^{\text {th }}$ order harmonic is found to be the dominant harmonic with the THD of $30.69 \%$. The controller derives the $180^{\circ}$ phase shifted $5^{\text {th }}$ harmonic component as the PWM reference and thereby enables the active filter to inject the compensating current. Fig. 9(iii) depicts the improved line current waveform with active power filter and the corresponding injected filter current is displayed in Fig. 9(iv). With active power filter, the amount of dominant harmonics in the line current is significantly reduced as listed in Table III, which results a more sinusoidal line current with the reduction in THD from $30.69 \%$ to $5 \%$ in FFT method and $4.68 \%$ in SRF method.

\section{TABLE III COMPARISON OF HARMONIC COMPONENTS WITH} AC-DC-AC CONVERTER AS LOAD

\begin{tabular}{|c|c|c|c|}
\hline \multirow{3}{*}{$\begin{array}{c}\text { Significant } \\
\text { Harmonics/THD }\end{array}$} & \multicolumn{3}{|c|}{ Magnitude (\%) } \\
\hline & \multirow{2}{*}{$\begin{array}{l}\text { Without } \\
\text { Filter }\end{array}$} & \multicolumn{2}{|c|}{ With Filter } \\
\hline & & FFT & SRF \\
\hline $3^{\text {rd }}$ & 15.79 & 3.22 & 2.92 \\
\hline $5^{\text {th }}$ & 22.35 & 1.35 & 1.40 \\
\hline $7^{\text {th }}$ & 4.05 & 0.47 & 0.49 \\
\hline $11^{\text {th }}$ & 2.32 & 0.16 & 0.13 \\
\hline $13^{\text {th }}$ & 2.95 & 0.10 & 0.10 \\
\hline THD & 30.69 & 5.00 & 4.68 \\
\hline
\end{tabular}
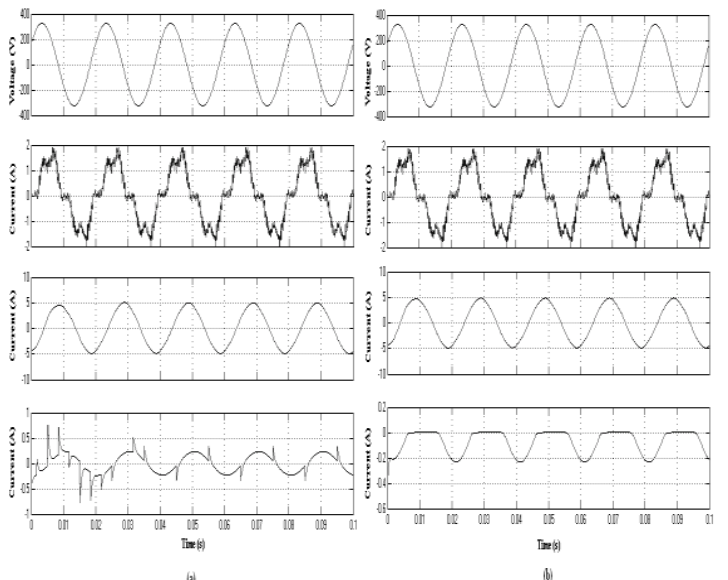

Fig.9. AC-DC-AC converter (a) FFT method (b) SRF method: i) input voltage ii) Line current without filter iii) Line current with filter iv) APF current

\section{Three phase unbalanced supply voltages}

The performance of the proposed scheme is also verified by simulating variation in the supply voltage. The unbalanced source voltages applied are

$$
\begin{gathered}
v_{a}=311 \sin \omega t \\
v_{b}=250 \sin \left(\omega t-150^{\circ}\right) \\
v_{c}=250 \sin \left(\omega t+90^{\circ}\right)
\end{gathered}
$$


Fig.10(i) shows the supply voltage corresponding to (1) (3). Without filter the THD of the line current is $18.07 \%$ and the $3^{\text {rd }}$ harmonic is found to be the dominant harmonic as displayed in Table IV. The non-sinusoidal line current waveform without APF is displayed in Fig.10 (ii). The closed loop controller derives the PWM reference for the multilevel inverter from the $3^{\text {rd }}$ harmonic component and thereby enables the inverter to inject compensating current in shunt with the line. Fig. 10(iii) depicts the improved line current waveform with the active power filter and the corresponding filter current is displayed in Fig. 10(iv). With APF the line current THD is significantly reduced to $11.43 \%$ in FFT method and $11.40 \%$ in SRF method and the reduction in corresponding dominant harmonic components are listed in Table IV.

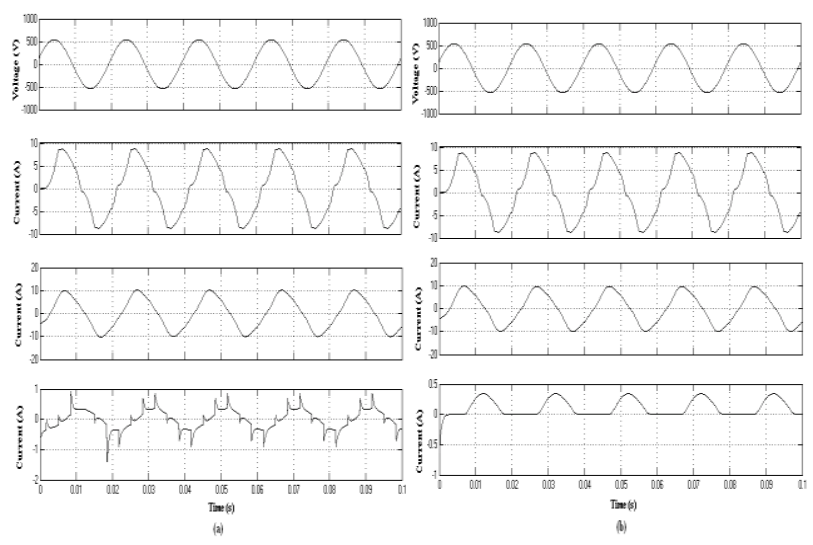

Fig.10. Unbalanced source voltage (a) FFT method (b) SRF method: i) input voltage ii) Line current without filter iii) Line current with filter iv) APF current

TABLE IV COMPARISON OF HARMONIC COMPONENT WITH AND WITHOUT SHUNT APF -UNBALANCED SOURCE VOLTAGE

\begin{tabular}{|c|c|c|c|}
\hline \multirow{2}{*}{$\begin{array}{c}\text { Significant } \\
\text { Harmonics /THD }\end{array}$} & \multicolumn{3}{|c|}{ Magnitude (\%) } \\
\hline & $\begin{array}{c}\text { Without } \\
\text { Filter }\end{array}$ & FFT & SRF \\
\hline $3^{\text {rd }}$ & 12.90 & 10.87 & 10.87 \\
\hline $5^{\text {th }}$ & 7.52 & 1.01 & 1.09 \\
\hline $7^{\text {th }}$ & 0.43 & 0.37 & 0.38 \\
\hline $11^{\text {th }}$ & 0.86 & 0.39 & 0.41 \\
\hline $13^{\text {th }}$ & 1.50 & 0.32 & 0.34 \\
\hline THD & 18.07 & 11.43 & 11.40 \\
\hline
\end{tabular}

\section{CONCLUSIONS}

MATLAB/SIMULINK power system toolbox is used to simulate the proposed system. Simulation results show that the dominant harmonics in the line current and total harmonic distortion have been reduced significantly. In this paper, reference currents have been generated using two different harmonic detection methods such as FFT and SRF. The FFT reduces the amount of time for calculation by using the number of sampled points $\mathrm{N}$, which is a power of two. However, if the load current varies in every period or in every few periods, the FFT algorithm may not provide sufficient information on-line to follow the harmonic content of the load. SRF overcomes this problem and also it is inferred from the simulation results that the reduction in THD is better in SRF method than FFT method.

\section{REFERENCES}

[1] C. Melhorn, T. Davis, G. Beam, "Voltage Sags: Their Impact on the Utility and Industrial Customers," in IEEE IAS Trans. on Ind. Appl., Vol. 34, No. 3, May/June 1998, pp. 549-558.

[2] G Moleykutty George and Kartik Prasad basu, "Three phase shunt active power Filter," American Journal of applied sciences, 2008

[3] Cristian Lascu, Lucian Asiminoaei, Ion Boldea and Frede Blaabjerg, "High performance current controller for selective harmonic compensation in active power filters," IEEE Trans. Ind.Appl., vol.22, no.5, pp. 1826-1834,Sep.2007.

[4] H M. Postan, A. R. Beig, "A three phase active filter based on three level diode clamp inverter," IEEE Trans. Ind. Appl., Jan.2008.

[5] Stockholm, Sweden, "Harmonic currents, static VAR systems," ABB Power Systems, Inform. NR500-015E, Sept. 1988, pp. 1-13.

[6] S. A. Moran and M.B. Brennen, "Active power line conditioner with fundamental negative sequence compensation," U.S. Patent 5 384696, Jan 1995.

[7] P. Mattavelli, "A closed-loop selective harmonic compensation for active filters," IEEE Trans. Ind. Appl., vol. 37, no. 1, pp. 81-89, Jan./Feb. 2001.

[8] Peng Xiao, Ganesh kumar Venayagamoorthy and Keith A. Corzine, "Seven-level shunt active power filter for high-power drive systems," IEEE Trans. Power electron., vol.24, no.1, pp.6-13, Jan.2009.

[9] B Keith Corzine, Yakov Familiant, "A new cascade Multilevel H bridge drive," IEEE Trans. Ind. Appl., vol. 17, no. 1, pp. 125-131, Jan.2002.

[10] Jagdish Kumar, Biswarup Das, Pramod Agarwal, "Selective harmonic elimination technique for a multilevel inverter," NPSC, IIT Bombay, Dec.2008.

[11] K. Vardar, E. Akpınar, T. Sürgevil, "Evaluation of reference current extraction methods for DSP implementation in active power filters," Electric Power Systems Research, vol.79, pp. 1342-1352, 2009.

[12] S. Rechka, E. Ngandui, J. Xu, P. Sicard, "A comparative study of harmonic detection algorithms for active filters and hybrid active filters," IEEE PESC, vol. 1, pp. 357-363, 2002.

[13] S. Rechka, E. Ngandui, J. Xu, P. Sicard, "Performance evaluation of harmonics detection methods applied to harmonics in presence of common power quality problems," ELECTRIMACS, pp. 363-375, 2002.

[14] S. Bhattachharya, T.M. Frank, D.M.Divan, B. Banerjee, "Active filter system implementation," IEEE Ind. Appl. Magazine, vol. 4, pp. 47-63, 1998.

[15] M. Aiello, A. Cataliotti, V. Cosentino, S. Nuccio, "Synchronization techniques for power quality instruments," IEEE Trans. Instrument. Meas. Vol. 56, pp. 1511-1519, October 2007.

[16] S. A. Bashi, N. F. Mailah, M.Z. Kadir, K.H. Leong, "Generation of triggering signals for multilevel converter," European Journal of Scientific Research, ISSN, vol.24, no.4, pp. 548-555, 2008. 